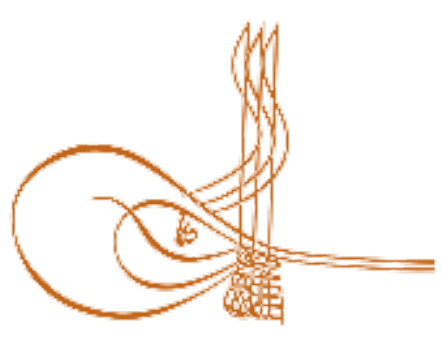

www.turkishstudies.net/language
Turkish Studies - Language and Literature

eISSN: 2667-5641

Research Article / Araștırma Makalesi

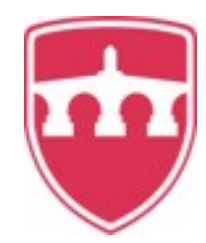

INTERNATIONAL

BALKAN

UNIVERSITY

Sponsored by IBU

\title{
“Drina Köprüsü” Romanı Üzerine Bir Tahlil Denemesi ${ }^{1}$
}

An Analitical Essay on the Novel Titled "The Bridge on the Drina"

\author{
Sezen Canatan ${ }^{*}$
}

\begin{abstract}
Ivo Andrić is one of the Yugoslav authors who has won the Nobel Prize in Literature with "The Bridge on the Drina". The events described in the novel take place in the town of Višegrad. The author chose the bridge as the protagonist of The Bridge on the Drina, which connects the two sides of the town and establishes a connection between the eastern and western culture. The Bridge on the Drina has both uniting and separating sides to it. In a short time, the bridge became the most secure pass connecting Bosnia to Serbia and then to other territories of the Ottoman Empire. It helped the town grow and develop and became a place where important events occurred, historic moments experienced. From the day it was constructed until now, it became a witness to Visegrad Serbia revolts, occupation of Bosnia and Herzegovina by the Austrians, 1912 Balkan Wars and cholera epidemics. While the Muslims lived on the right bank of the bridge, the Christians lived on the left side bank. The bridge is the common place of the two communities. The events have unfolded over time but the bridge has always remained the same. Ivo Andric is a real humanist. This characteristic of him has been reflected in the work. The work is neither biased towards the modernists nor the traditionalists. It tries to understand each person. "The Bridge on the Drina" novel has been studied under the titles of "Plot, main theme, time, location, language and style" in this essay. The interaction between people and locations was examined.
\end{abstract}

Structured Abstract: Ivo Andrić is one of the Yugoslav authors who has won the Nobel Prize in Literature with "The Bridge on the Drina". The events described in the novel take place in the town of Višegrad. Mehmed PašaSokolović (Sokollu Mehmed Pasha) is also from Višegrad. He was sent to Enderun (Imperial Institution) for education. The children were chosen by the method of Devshirme (Recruitment of children as blood tax, to be converted to Islam and receive Janissary training and education). They were first given to Muslim Turkish families and later on educated in palaces. The brightest were assigned to higher ranks in the Ottoman administration. In memory of the place he grew up and unable to forget his departure, Sokolović (Sokollu) had The Bridge on the Drina built as debt of gratitude to Višegrad.

The story revolves around The Bridge on the Drina, which connects the two sides of the town and establishes a connection between the eastern and western culture. The Bridge on the Drina has both uniting

\footnotetext{
${ }^{1}$ Bu makale İNCSOS Üsküp’te sunulan sözlü bildirinin makale formatında hazırlanmış hâlidir.

* Öğretmen, Milli Eğitim Bakanlığı, Türk Dili ve Edebiyatı

Teacher, Ministry of National Education, Turkish Language and Literature

ORCID 0000-0002-3065-8810

sezencnt@gmail.com

Cite as/ Atıf: Canatan, S. (2020). "Drina Köprüsü” romanı üzerine bir tahlil denemesi, Turkish Studies - Language, 15(1), 99-106. https://dx.doi.org/10.29228/TurkishStudies.39306

Received/Geliş: 16 October/Ekim 2019

Accepted/Kabul: 24 March/Mart 2020

Copyright $\mathbb{C}$ INTAC LTD, Turkey
} 
and separating sides to it. While the Muslims lived on the right bank of the bridge, the Christians lived on the left side bank. The bridge is the common place of both communities. The events have unfolded over time but the bridge has always remained the same. Ivo Andric is a real humanist. This characteristic of him has been reflected in the work. The work is neither biased towards the modernists nor the traditionalists. It tries to understand each person. "The Bridge on the Drina" novel has been studied under the titles of "Plot, main theme, time, location, language and style" in this essay. The interaction between people and locations was examined. The study has been conducted in the nature of novel review, novel analysis.

The plot consists of a sequence of interconnected and independent events. The construction of the Bridge of Drina, Serbian uprisings, cholera outbreaks, floods, the invasion of Bosnia and Herzegovina by Austria, the introduction of the railroads, the First Balkan War, the assassination of the Austrian prince Ferdinand in June 1914 by a Serbian youngster, Austro-Hungarian occupation of Serbia and the attempted annihilation of the bridge with dynamites are amongst the historical events depicted in the novel. Along with this, events influencing the lives of individuals such as Fata's jump off into River Drina after being forced to marry someone she doesn't consent to; depiction of the gambler Glasinčanin's semi realistic, semi fabulous story of his passion for gambling; lives of single-eyed Salko and tavernerLotika; public impalement of Radisav have also been included in the novel. We have discussed the events that deeply affect the society, influence the chronology and act as trigger points when studying the storyline in our essay.

First sequence of events that unfold in the novel is the construction of the Bridge on the Drina. The construction of the bridge commences following the arrival of Abidaga and Tosun Effendi the mason, who were selected for the construction, and the stern statements made by them publicly. At the end of three years, the construction is still not completed. Learning that the troubles regarding the construction were caused by Radisav, Abidaga gets Radisav apprehended. Radisav is impaled by Gypsy Merdžan.

The second turn of events in the novel begins with the floods. The River Drina overflows in the first and last spring of each year but does not cause great damage. However, the floods which take place every 2030 years leave profound traces in the lives of the people of Višegrad as much as the rebellions and wars. These disasters act as years-long setbacks and the people alive spend the rest of their lives repairing buildings throughout such period. One of the most recent flooding of the town had taken place in the late 18th century. The townspeople, exhausted and sleeplessness from the flood watches, surrender a deep sleep after seeing the water of Drina not rising. And the water catches them off guard. The water of the River Drina rises like never before and overflows and covers the town in a red mud.

The third sequence of events in the novel span around the uprisings in Serbia. The rebels reach a location that is two hours away from Višegrad. A fire has been started. The Serbs consider the fire as a fire of salvation and jubilantly greet it whereas Muslims wish the same fire to extinguish and pray God for the restoration of peace and order as usual. After a while, the fire on the Mount Panos distinguishes and the uprising is driven away from Ujitsa. An outpost is established in Kapija and a watch is stood. A young Serb chanting a song mentioning the name of Georg Fedun who started the uprising is apprehended by the Muslims and impaled. Following the suppression of the Serbian rebellion, the regular social life is restored.

The fourth turn of events in the novel is the somber story of the Bosnian girl Fata, who threw herself off the Bridge on the Drina because she was forced to marry a young man she did not have an affection for. Herzegovina.

The fifth series of events in the novel is the Austro-Hungarian occupation of Bosnia and

The sixth set of events in the novel is the introduction of the railroads in Višegrad. The AustroHungarian Empire introduces railroads to Višegrad within the scope of a project called "Eastern Railways".

The last chain of events in the novel is the assassination of the heir of the Austrian-Hungarian Emperor by a Serbian in Sarajevo.

The historical events spanning a period of three hundred and fifty years, to which the Bridge on the Drina is a witness, has been depicted in the novel. The events unfold in a chronological order. The time expressions are prominent in the novel, timeframes are lucid.

Ivo Andric, who can be regarded as a romantic, has worked on individual themes along with social themes. This has helped adding sentiment to the work and saved it from becoming a dull novel based on historical information.

Turkish Studies - Language, 15(1) 
Written in plain language, Ivo Andric likes utilizing descriptions and portrayal. The events in the novel unfold in a flow. Lack of ambiguity, use of a fluent language saved the novel from becoming monotonous and facilitated comprehension.

The Bridge on the Drina has been endowed a soul in the novel. It is a silent witness. The author picked the bridge as the main character of the novel. The bridge is the common place where Christians and Muslims spend time. It has a connective role. It has become a part of social life. The significance of the bridge, which has a very important role in the life of the townspeople, has been elegantly expressed at the end of the novel. Seeing the collapse of the 7th column of the Bridge on the Drina, Ali Hodja can't stand it and passes away. The collapse of the bridge was considered equal to the death of a human being.

We can perceive the influence of the concept of identity in the novel. At the time of the occupation, Muslims gathered in the homes of the Muslims and the Christians in the homes of Christians. Although mentioning differences, a bond between the cultures has been established. The friendship between Priest Nicola and Mullah Ibrahim is an outstanding embodiment of this bond.

In conclusion, the novel of The Bridge on the Drina by Ivo Andric has become one of the most successful works that conduced to acknowledgement of both Bosnia which has shared a long-term common fate with the Ottoman Empire and the people of Bosnia.

Keywords: Balkan Litertaure, Analysis, The Bridge on Drina, Novel, Ivo Andric

Öz: Drina Köprüsü adlı eseriyle Nobel Edebiyat Ödülü kazanan İvo Andriç Yugoslav yazarlardan biridir. Eserde anlatılan olaylar Vişegrad kasabasında geçer. Sokollu Mehmet Paşa da Vişegradlıdır. Eğitim görmek amaciyla Enderun Mektebine götürülmüştür. Çocukla rmektebe devşirme usulüyle seçiliyordu. Önce Müslüman Türk ailelerin yanına yerleştiriliyor daha sonra saraylarda eğitim görüyorlardı. Bu eğitimden başarıyla geçenler Osmanlı yönetiminde üst düzeyde görev alabiliyordu .Yaşadığı yeri ve oradan ayrılışını unutmayan Sokollu, Drina Köprüsü’nü yaptırarak Vişegrad'a gönül borcunu ödemiştir. Yazar romanda iki yakayı birleştiren, bununla birlikte doğu ile batı kültürü arasında bağ kuran Drina Köprüsü’nü başkahraman olarak seçmiştir. Drina Köprüsü'nün hem birleştirici hem de ayırıcı özelliğivardır. Köprü kısa bir zamanda Bosna'yı Sırbistan'a oradan da Osmanlı İmparatoruğunun öteki bölgelerine bağlayan en güvenilir geçit hâline gelmiştir. Kasabanın büyüyüp gelişmesine yardım etmiş,önemli olayların geçtiği, tarihi dönüm noktalarının yaşandığı bir mekân olmuştu. İnşa edildiği günden bugüne Vişegrad Sırbistan isyanlarına, Bosna-Hersek'in Avusturyalılar tarafından işgaline, 1912 Balkan Savaşlarına, kolera salgınlarına tanık olmuştur. Köprünün sağ kıyısında Müslümanlar yaşarken sol kıyısında Hristiyanlar yaşamaktadır. Köprü ikitopluluğun da ortakmekânıdır. Yaşanan olaylar değişmiştir ama köprü hep aynıkalmıştır. İvo Andriç gerçek bir hümanisttir. Bu özelliği esere de yansımıştır. Eser ne yenilikçileri ne de gelenekçilerin tarafını tutar. Her insanı anlamaya çalışır. Bu çalışmada Drina Köprüsüromanı "Olay örgüsü, tema, zaman, mekân, dil ve üslup" başlıkları altında değerlendirilmiştir. Kişiler ile mekân arasındaki etkileşim irdelenmiştir.

Anahtar Kelimeler: Balkan Edebiyatı, Tahlil, Drina Köprüsü, Roman, Ivo Andriç

\section{Giriş}

Ivo Andriç, 1686-1851 yılları arasında Bosna eyaletinin merkezi olan Travnik kasabasında,10 Ekim 1892 tarihinde doğdu. Çok küçük yaşta babasını kaybetti. Genç yaşta dul kalan ve Vişegrad'lı olan annesi oğlu ile birlikte Vişegrad'taki ailesinin yanına gitti. Böylece Ivo Andriç çocukluğunu, delikanlılık çağının büyük bir bölümünü romanına konu olan olayların geçtiği Drina Irmağı kıyısındaki bu küçük kasabada geçirdi. İlk ve orta öğrenimini ise Viyana, Zagreb, Krakov ve Graz üniversitelerin de yaptı. Bu üniversitelerde felsefe, Slav tarihi ve edebiyatı okudu. Ivo Andriç, üniversite sıralarında politikayla ilgilenmeye başladı. Avusturya-Macaristan İmparatorluğunun sınırları içinde yaşayan Slav ulusunun kurtuluşunu ve birliğini sağlamaya çalışan devrimci gençlik örgütüne girdi. 1914 Haziranı'nda Avusturya veliahtı Ferdinand, bu örgüte bağlı gençlerden biri tarafindan Saraybosna'da öldürüldü. Bu örgüte bağlı birçok Sırp genci gibi Ivo Andriç'de bu olayla ilgili olarak tutuklandı. 1917 yılında aftan yararlanarak yarıda kalmış olan 
üniversite öğrenimini tamamladı. İkinci Dünya Savaşına kadar çeşitli ülkelerde konsolosluk ve elçilik yaptı (Andriç,2005:7).

Edebiyata olan ilgisi şiirle başlayan sanatçı 1918'de şiirlerini Ex Ponto adlı kitapta derledi. 1920 'de ise ilk hikâyesi olan Ali Cercelez Yolu'nu yayımladı. Ivo Andriç kendisine ün kazandıran Travnik Kronika, Drina Köprüsü ve Matmazel isimli eserleri 1945 yılında yayımladı. Bu eserlerde Bosna'y1 anlattı. Drina Köprüsü romanı yazarın en önemli eseridir. 1961 yılında yazara Nobel Edebiyat ödülünü kazandırmıştır. Bu eserde Vişegrad kasabasının 16.-20. yy'lardaki macerası anlatılmıștır.

\section{Drina Köprüsü Romanının Tahlili \\ 1.Olay Örgüsü}

Romanın ilk olay halkası Drina Köprüsü'nün inşaatı dır. Köprünün yapımı için seçilen Abid Ağa ve Mimar Tosun Efendi'nin kasabaya gelip halka sert açıklamalar yapmasının ardından inşaata başlanmış olur. Üç yılın sonunda inşaat hâlâ bitmemiştir. Abid Ağa'nın baskıcı ve sert tavrından şikayetçi olan Hristiyan köylüleri Radisav'ın etkisinde kalmaya başlar. Radisav, inşaatın sabote edilmesi konusunda köylüleri ikna eder. Radisav başarılı olur ve köprü inşaatına geceleri zarar verilir. Köprü yapımıyla ilgili sorunların kaynağının Radisav olduğunu öğrenen Abid Ağa, Radisav'1 yakalatır. Radisav, Çingene Mercan tarafından kazığa geçirilir. Bu infaz Sırp köylüsünü derinden etkiler.

Abid Ağa'nın zulmü, işçilere para vermediği gibi olayların Sokullu'nun kulağına gitmesi üzerine Abid Ağa'nın yerine Arif Bey getirilir. Arif Bey, Abid Ağa'nın tam zıttı özelliklere sahiptir. Halka çok iyi davranır. İnşaatın üçüncü yılının sonunda büyük bir taş bloğunun taşınması sırasında sorun çıkar. Sorunun çözümüyle ilgilenen Arap, taş bloğunun altında kalarak ölür. Beş yılın sonunda köprünün yapımı tamamlanır.

Romanın ikinci olay halkası sel baskınlarıyla başlar. Drina Nehri, her yılın ilk ve son baharlarında taşar ama büyük zararlara sebep olmaz. Buna karşın 20-30 yılda bir olan sel baskınları Vişegrad'lıların hayatında isyan ve savaşlar gibi derin izler bırakır. Bu afetler kasabayı birkaç yıl geriye götürür. $\mathrm{O}$ zaman diliminde yaşayan halk ömrünün geri kalanını binaları onarmakla geçirir. Kasabanın en son sel felaketlerinden biri 18. yüzyılın sonlarına doğru olur. Sel nöbeti tutan ve uykusuzluktan bitkin bir hâle dönen kasaba halkı Drina'nın kabarmadığını görünce derin bir uykuya dalar. Su onları böylece gafil avlar. O gece Drina hiç görülmemiş bir şekilde kabarır ve kıpkırmızı bir çamur halinde kasabanın üzerine taşar. Kasabanın en zenginlerinden biri olan Suliağa Osmonoviç'in atının kişnemeye başlamasıyla kasaba halkı felakete uyanır. Afet farklı dinlerden insanları bir araya getirir. İki gün sonra sular çekilir ve güneş görünür. Suların çekilmesiyle de meydana gelen zarar belli olur.

Romanın üçüncü olay halkası Sırbistan'da çıkan ayaklanmadır. Asiler Vişegrad'ın iki saat ilerisine kadar gelir. Bir ateş yakılır. Sırplar bu ateşi kurtuluş ateşi olarak görüp heyecanla karşılarken Müslümanlar ise aynı ateşin sönmesi, barışın ve eski düzenin geri gelmesi için Allah'a dualar ederler. Bir süre sonra Panos Tepesi'ndeki ateşler kaybolur ve ayaklanma Üjitsa dolaylarından sürülür. Kapiya'da bir karakol kurulur ve nöbet tutulur. Ayaklanmayı başlatan Kara Corc'un adının geçtiği bir şarkıyı söyleyen Sırplı genç, Müslümanlar tarafından yakalanır ve kazığa geçirilir. Bastırılan Sırp isyanının ardından sosyal hayat normale döner.

Romanın dördüncü olay halkası istemediği bir delikanlıya verildiği için kendini Drina Köprüsünden atan Boşnak kızı Fato'nun acıklı hikâyesidir. Çevre köylerinden biri olan Avdaga'nın Fato adında çok güzel bir kızı vardır. Yine çevre köylerinden tüccar Mustafa Bey Hazmiç’in oğlu Nail, Fato’yu sevmektedir. Avgada Osmanagiç kızı Fato’yu Mustafa Bey Hazmiç'in oğluna verir. Bir taraftan istemediği bir evlilik bir taraftan da babasının verdiği söz karşısında ne yapacağını bilemeyen Fato dügün alayıyla birlikte köprüden geçerken atını yavaşlatır ve kendini Drina 
Nehri'nin sularına bırakır. Kızın ölüsü bir balıkçı tarafından bulunur. Fato'nun babası Avdaga o günden sonra kasabaya inmez. O kış derdini kimseye anlatmadan bir öksürük nöbeti sırasında ölür. Mustafa Bey Hazmiç ise ertesi yıl oğlunu başka bir kızla evlendirir.

Romanın beşinci olay halkası Bosna-Hersek'in Avusturya tarafından işgalidir. Kara Corc ayaklanmasından 70 yıl sonra Plevlie müftüsü birkaç kişiyle birlikte kasabaya gelir. Burada Avusturyalılara karşı direnme hareketi hazırlamak için çalışırlar. Müftü bir süre sonra Osman Karamanliya adlı adamı gönderir. Karamanliya, Müslümanlarla konuşmaya çalışır. Ali Hoca denilen kişi Karamanliya'dan daha farklı düşünür ve aralarında sert bir tartışma çıkar. Karamanliya Ali Hoca'yı kulaklarından Kapiya'ya çiviler. Ac1 içinde kıvranan Ali Hoca'yı Avusturyalılar kurtarır. İşgalciler Kapiya'da Türkçe yazılı taşın olduğu yere beyaz bir kâğıt asarlar. Bu ilanda İmparator halka seslenir. Avusturya birlikleri ertesi gün resmen kasabaya girer. Bu işgalle birlikte kasabada büyük değişiklikler yaşanır. İşgalin dördüncü yılında her şey yerli yerine oturur. Türklerin zamanındaki sakin yaşam yoktur artık. Kasabaya yeni askerî birlikler gelir ve Kapiya'ya tekrar nöbetçi konulur. Bu olayların üzerinden iki yıl geçer. Herkes yaşanan sorunları unutmaya başlarken asker toplama sorunu çıkar. Sosyal durumu ya da dini ne olursa olsun bütün gençlerin askerlik görevi yapması gerekir. Doğu Hersek'te bir ayaklanma çıkar. Bosna'da teşkilatlandırılmış bir direnme olmaz ama isyan Foça ve Gorajda'dan yakınlardaki bucaklara kadar yayılır. Bu sebeple Kapiya'ya sürekli nöbetçiler konulur. Nöbetçiler şüpheli gördükleri yolcuları durdurur, üstlerini başlarını arar.

Romanın altıncı olay halkası Vişegrad'a demir yolunun gelmesidir. Avusturya-Macaristan imparatorluğu "Doğu Demir Yolları" denilen bir proje kapsamında Vişegrad'a demir yolu getirir. Saraybosna yoluyla bütün batı dünyasına yapılan her türlü taşıma işleri demir yolunun gelmesiyle birlikte Drina'nın sağ kıyısından yapılmaya başlanır. Sol kıyı ve onunla birlikte de köprü felce uğrar. Köprüden sadece sol kıyıda oturan köylülerin yük taşıyan atlarıyla, ormanlardan istasyona odun taşıyan öküz ya da at arabaları geçer. Dünya "Illhak Krizi" olarak anılan ve köprü ile yanındaki kasabaya kadar ulaşan o gerginlik çabuk geçer.

Romanın son olay halkası Avusturya-Macaristan imparatoru veliahtının Saraybosna'da bir Sırp tarafından öldürülmesidir. 1912 yılında çıkan Balkan Savaşı'nı Sırplar kazanır. Türkler toprak kaybederken Drina Köprüsü işlevini yitirir. Vidovdan Yortusu günü Sirplar Mezalin denilen yerde bir eğlence düzenlerler. Jandarmaların gelmesiyle eğlence birden kesilir. Sırplar, Arşidük Fransua Ferdinand'ın bir Sırp tarafından öldürüldüğünü öğrenirler. Birkaç Sırp tutuklanır. Glasinçanin ve arkadaşları Sırbistan'a kaçmaya karar verir. Köprüde yakalanan birkaç Sırp idam edilir. Birkaç gün sonra da köprü ve kasaba Sırbistanlı Sirplar tarafindan topa tutulur. Bombardıman günlerinde Müslümanlar Müslümanların evlerinde, Sırplar Sırpların evlerinde toplanır. Ali Hoca'nın evinde Muyaga Mutapsiç adlı bir göçmen Müslüman ailesi kalır. Avusturyalılar, köprünün saldırıya uğraması ihtimaline karşı Sırpların ileri gelenlerinden bazılarını rehin tutar. Köprüye bir şey olması hâlinde rehineler öldürülecektir. Bir Alman birliği kasabaya gelir. Bir süre sonra demir yolu kesilir, askerî birlikler Drina'nın sağ kıyısından ayrılır. Avusturyalılar kasabayı terk eder. Büyük bir patlama olur. Ali Hoca bu sırada dükkânındadır. Dükkânın bütün malzemeleri karışır, Ali Hoca bayılır. Kendine geldiğinde Drina Köprüsünün 7. sütununun yıkıldığını görür. Yaşadığı şokun ardından evine gitmek üzere yokuş çıkarken birden düşer ve kısa titreyişlerle Allah'a ruhunu teslim eder.

\section{Tema}

Ivo Andriç eserlerinin çoğunda konu olarak Bosna'yı işlemiştir. Bosna'nın Osmanlı egemenliği altına girişinden bugüne kadar geçen olayları, şehirlerini, kasabalarını, efsanelerini ve masallarını anlatmıştır. Yazar hümanisttir. Bu sebeple farklı dinlerin ve soyların kaynaştığı bu bölgede din ve ırk ayrımı yapmadan, olaylarda yer alan kişilere eşit bir sevgi ve ilgi göstermiştir. 
"Onun vazgeçemediği temalar arasında insan ve toplumsal ve siyasal değişiklikler içinde biçimlenen insanın yapısı da önemlidir. Bir söyleşisinde; 'mümkün olduğu kadar kişioğlunun değişik yazgısına inmek, kişioğlunun ruhunu hareket hâlinde ama yüce bir sevgiyle, görülür bir aydınlıkla anlatmak gerekir' diyen İvo Andriç'in misyonu ve eserleri, Avrupa'da bugün millet olarak siyaset sahnesinde yer alan milletlerin teşekkülünde önemli rol sahibi olan romantik yazarlar kategorisinde değerlendirilir"'(Karaca:2003).

Eser iç içe olaylardan oluşmuştur. Olaylar Vişegrad'ta ve aynı yerde bulunan Drina Köprüsü'nde geçer. Bu kadar dar bir çevrede olayların peş peşe yaşanması bizi mekâna bağlı kılar. Mekân aynıdır fakat olaylar birbirinden çok farklıdır. Eserin ilk bölümünde Sokullu'nun köprüyü niçin yaptırdığına değinilmiştir.

"Vişegrad-Bosna'da bulunan Drina Nehri üzerindeki köprü,16. yüzyılın ortalarında Bosnalı bir köylünün oğlu olarak dünyaya gelen ve Osmanlı İmparatorluğunda veziriazamlığa kadar yükselerek Sokullu Mehmet Paşa (doğduğundaki adı Sokolović) (1506-79) tarafindan inşa ettirilmiştir. Sokullu gençliğinde padişahın ordusuna asker alınmış, kökenlerine olan bağlılı̆̆ını göstermek için de Drina üzerine bir köprü yaptırmıştır. Doğduğu yerde hatırlanmak için gösterdiği bir başka iyi niyet de kan kardeşini Sırp Kilisesi'ne patrik olarak atamaktır.”(Seyhan,2011: 17)

Sokullu bağlılık duygusuyla hareket etmiştir. Doğduğu topraklara olan vefa borcunu köprü yaptırarak ödemeye çalışmıştır.

Romanda kişilerle beraber iyi-kötü çatışmasını görürüz. Abid Ağa gibi insanları diri diri kazığa geçiren bir zalimin karşısına Arif Bey gibi dürüst, yumuşak birini çıkarmıştır.

Babasının isteği üzerine sevmediği biriyle evlenmek zorunda bırakılan Fato bu durumu kabullenmeyip ölümü tercih etmiştir. Yazar ne istediğini bilen, güçlü karakterler yaratmıştır. Bu karakterler sonu ölüm bile olsa istemedikleri bir durumu kabullenmemişlerdir.

Avusturya-Macaristan yönetimindeki Bosna'da işgalle birlikte sosyal ve ekonomik hayat değişmiştir. Burada değişim temasına rastlarız. Eski günler özlense de var olan yönetime, hayat tarzına alı̧̧ılmıştır.

Demir yolunun kasabaya gelmesi Drina Köprüsü'nün kullanılmamasına sebep olur. $\mathrm{Bu}$ durum yalnızlık temasıyla ilişkilidir. Hayatta her şeyin bir sonu vardır. Drina Köprüsü de kendi sonuna yaklaşmaktadır. Demir yolu Drina Köprüsü’nü yalnızlaştırır ve bir başına bırakır.

Romanda Rahip Nikola ile Molla İbrahim'den bahsedilir. Bu iki farklı kimlik birbiriyle iyi dosttur. Özellikle bu kişilerin ilişkisinden yola çıkılarak dostluk ama dil, din, 1rk farkı gözetilmeyen dostluk vurgulanmıştır.

Romanın sonlarına doğru yıllarca ayakta kalan, yaşanılan her şeye tanık olan dilsiz Drina Köprüsü'nün bir sütununun yıkılışı anlatılır. Bu da Ali Hoca'nın gözünden verilir. Ali Hoca'da tıpk1 Drina Köprüsü gibi uzun yıllar kasabada olup bitene şahit olmuştur. Ölüm teması Drina Köprüsü'nün bir sütununun yıkılması üzerine yaşadığı şokun etkisiyle ruhunu teslim eden Ali Hoca üzerinden verilmiştir.

\section{Zaman}

Roman, 16. yüzyılın ilk çeyreğinden 20.yüzyılın ilk çeyreğine kadar olan olayları anlatır. Zaman nettir eserde. '1878 yılının yaz başlangıcında'(s.121) gibi ifadelere yer verilmiştir. Romanda zaman tarihsel olaylarla beraber ilerler. 1803 Sirp Ayaklanması, 1914'te Avusturya veliahtının bir Sırplı tarafından öldürülmesi buna örnektir. "Kapiya'da konuşulan şeylerin üstünden 30 yıla yakın zaman geçti."(Andriç,20015: 103) cümlesinde olduğu gibi zaman ile ilgili belirgin ifadelere rastlamaktayı.

\section{Mekân}


Mekân Vişegrad kasabası ve Drina Köprüsü’dür. Kitabın ilk bölümünde Drina Nehri’nin ve Vişegrad kasabasının tasviri yapılır.

"Drina daha çok, sarp dağlar arasındaki dar boğazlarda ya da derin uçurumlar içinde akar. Ancak birkaç yerinde kıyıları geniş vadiler hâlinde açılır, kâh bir kıyısında kâh her iki kıyısında insanların yaşamasına ve tarıma elverişli bazen düz bazen dalgalı ama bereketli ovalar meydana getirir. Bu ovalardan birisi de burada, tam Drina'nın Butko kayalarıyla Uzanviçka dağlarının arasındaki dar boğazdan ani bir dirsek yaparak meydana çıktığ başlar.'(Andriç,2005: 13)

Nehrin üstündeki Drina Köprüsü'nün uzunluğu yaklaşık 250, genişliği ise 10 adımdır. Köprünün tam orta yerinde birbirine eşit iki biçimde genişler. Teraslar ortadan geçen araba yolunun iki katı genişliğindedir. Köprünün bu bölümüne "Kapiya" adı verilir. Kapiya romanda asıl belirleyici mekândır. Kapiya ayaklanmaların, kavgaların olduğu; arkadaş sohbetlerinin yapıldığı, asilerin idam edildiği, sevmediği biriyle evlenmek istemeyen Fato'nun kendini nehrin sularına bıraktığı yerdir. Kadınlar Avustralyalıların döneminde rahat bir şekilde burada zaman geçirir.

Romanda mekân ve insanlar arasında bağlantı kurulur. Köprü Vişegrad halkıyla bütünleşmiştir. "Köprü kasabalıların karakterini, kaderini de tayin eder. Vişegrad'lıların hayalperest olmaları, melankolik bir yapıya sahip olmalarındaki en büyük etken buradaki insanların Kapiya'da uzun saatler kalıp hayallere dalmaları olarak gösterilir.”(Bayram,2014:274)

\section{Dil ve Üslup}

Ivo Andriç'in geniş kitlelerce uzun yıllar okunmasının sebeplerinde biri de kullandığı dil ve üslubudur. Yazar temiz, sade bir dil kullanır. Romanı okumak ve anlamak anlaşılır dili sayesinde kolaylaşır. Eserde olaylar hâkim bakış açısı ve üçüncü tekil kişi tarafından aktarılır. Eser ilk okunduğu vakit anlatıcının yazar olduğu hissedilse bile bazen anlatılan olay bir yazarın anlatımından çıkar.

Mekânlarla ilgili bol bol betimlemeye başvurmuş olan sanatçı sıfatları epeyce kullanmıştır. Eserdeki şahısların tek yönlü olduğunu söylemek mümkündür. Şahıslar iyiler ve kötüler olmak üzere sınıflandırılabilir. Bu fikrin en önemli örneği Abid Ağa ile Arif Bey olarak gösterilebilir.

Yazar olayları okuyucunun zihninde canlandırma konusunda çok başarılıdır. Bize göre romanın en çarpıcı sahnelerinden biri Radisav'ın kazığa geçirildiği bölümdür. Bu heyecanlı sahne tüm ayrıntılarıyla verilmiştir. Okuyucu adeta kendini Radisav'ın yerinde hisseder.

“O sırada çekiç sesleri kesildi. Mercan, adamın sağ küreğinde kasların gerildiğini, derinin kabardığını görmüştü. Hemen bir ustura alarak o yeri haç biçiminde yardı. Soluk bir kan akmaya başladı. Gittikçe fazlalaştı. Bir iki vuruştan sonra, delinen noktadan kazığın demir ucu görünmeye başladı. Bu uç, sağ kulağın hizasına gelinceye kadar daha bir iki darbe vurdu. Adam artık kazığa büsbütün geçmişti. Şişe geçirilen bir kuzu gibi. Yalnız sivri ucu ağzından değil, sırtından çıkıyordu. Ne bağırsakları ne de ciğerleri zedelenmişti.’(Andriç,2005: 54)

\section{Sonuç}

Bu çalışmada İvo Andriç'e Nobel Ödülü kazandırmış olan Drina Köprüsü romanı incelenmiştir. İnceleme olay örgüsü, tema, zaman, mekân, dil ve üslup başlıkları altında yapılmıştır.

Olay örgüsü birbirine bağlı ve aynı zamanda bağımsız olayların sıralanmasından oluşur. Drina Köprüsü'nün inşaatı, Sırbistan isyanları, kolera salgınları, su baskınları, Bosna -Hersek'in Avusturya tarafından işgali, demir yolunun gelmesi,1912 Balkan Savaşı, 1914 Haziranı'nda Avusturya veliahtı Ferdinand'ın Sırplı bir genç tarafından öldürülmesi, Avusturya-Sırbistan Savaşı ve köprünün dinamitle yıkılmaya çalışılması romanda geçen tarihsel olaylardır. Bunun yanında istemediği biriyle evlenmek zorunda bırakılan Fato'nun kendini Drina'ya bırakması, kumarcı 
Glasinçanin'in yarı gerçek, yarı masal hâlinde anlatılan kumar tutkusu, tekgöz Salko'nun gazinocu Lotika'nın yaşamları, Radisav'ın herkesin gözü önünde kazığa geçirilmesi gibi bireylerin yaşamını ilgilendiren olaylar da romanda yer almıştır. Biz makalemizde olay örgüsünü işlerken toplumu derinden etkileyen, zamana yön veren başlangıç ifade eden olayları ele aldık.

Romada Drina Köprüsü'nün tanık olduğu üç yüz elli yıllık tarihî olaylar anlatılmıştır. Olaylar kronolojik bir sıralama ile verilmiştir. Eserde zaman ifade eden kelimeler belirgindir, net zaman dilimlerinden bahsedilmiştir.

Bir romantik olarak değerlendirebileceğimiz İvo Andriç toplumsal temalarla birlikte bireysel temaları da işlemiştir. Bu da eseri tarihî bilgilere dayalı kuru bir roman olmaktan çıkarıp esere duygu yüklemeye yardımcı olmuştur.

Son derece sade bir dille yazan İvo Andriç betimleme yapmayı sever. Eserde olaylar bir akış içinde verilmiştir. Anlam kapalılığının olmaması, akıcı bir dilin kullanılması romanı sıkıcı olmaktan kurtarmış, anlaşılmayı kolaylaştırmıştır.

Drina Köprüsü romanda ruh bulmuştur. Sessiz bir tanıktır o.Yazar, romanın baş kahramanı olarak köprüyü seçmiştir. Hristiyanlar ve Müslümanların zaman geçirdiği ortak mekândır köprü. Birleştirici bir rolü vardır. Sosyal hayatın bir parçası olmuştur. Kasaba halkının hayatında çok önemli bir yeri olan köprünün önemi romanın sonunda çok güzel ifade edilmiştir. Ali Hoca Drina Köprüsü'nün 7. sütununun yıkıldığını görünce buna dayanamaz ve ölür. Köprünün yıkılışı bir insanın ölümüyle bir tutulmuştur.

Romanda ayrıca kimlik kavramının etkisini hissederiz. İşgal zamanı Müslümanlar Müslümanların evinde, Hristiyanlar Hristiyanların evinde toplanmıştır. Farklılık ifade edilse de iki kültür arasında bir bağ da kurulmuştur. Rahip Nikola ile Molla İbrahim arasındaki dostluk bu bağın güzel bir ifadesi olarak romanda yer almıştır.

Netice itibariyle İvo Andriç ve Drina Köprüsü romanı, Osmanlı Devleti'nin çok uzun yıllar kader birliği ettiği Bosna'yı ve Bosna halkını tanımamıza vesile olan en başarılı eserlerden biri olmuştur.

\section{Kaynakça}

Andriç, I. (2005). Drina Köprüsü, İstanbul: İletişim Yayınları.

Bayram, S. (2014). Ivo Andriç’in Drina Köprüsü Adlı Romanı Bağlamında Hayatlara Uzanan Köprüler. Turkish Studies-International Periodical For The Literature and History of Turkish, 9(9), 271-282. https://doi.org/10.7827/turkishstudies.7058.

Karaca Nesrin, T. (2003). Ivo Andriç'in Uğursuz Avlu Romanında Hapishane ve Osmanlılar. Marmara Üniversitesi Türkiyat Araştırma Merkezi, 4-5 Aralık.

Kolcu, A. (2003). Ivo Andriç ve Drina Köprüsü Romanı. Türklük Bilimi Araştırmaları, 219-245

Seyhan, A. (2011). Modern Türk Romanı, İstanbul: İletişim Yayınları. 